\title{
Recomendaciones para la Prevención de la Transmisión Perinatal del Virus de la Inmunodeficiencia Humana en Costa Rica
}

Elaborado y revisado por Comisión Interhospitalaria de Terapia Antirretroviral CCSS: Oscar Porras M, María Paz León B, Gisela Herrera M, Antonio Solano Ch, Ignacio Salom E, Alfredo Messino J, Ricardo Boza C.

El desarrollo del conocimiento sobre la infección con el Virus de la Inmunodeficiencia Humana (VIH), en los aspectos de epidemiología, mecanismos de infección, respuesta inmunológica, uso de medicamentos antirretrovirales y posibilidades de prevenir la transmisión del VIH al ser humano, permite plantear una estrategia para reducir el porcentaje de niños y niñas que se infectan de su madre $\mathrm{VIH}+$ por los mecanismos de transmisión perinatal.

La estrategia de prevención de la transmisión perinatal se desarrolla durante el embarazo, el periodo de labor y las primeras 6 semanas de vida del recién nacido, y está basada en el hecho de que todas las actividades de prevención para la transmisión perinatal de VIH son costo-efectivas y evitan el manejo de pacientes con enfermedades crónicas y grados variables de discapacidad.

Esta estrategia esta sustentada en tres elementos:

Tamizaje de la mujer embarazada en la primera consulta prenatal, idealmente durante el primer trimestre, pero puede ser en cualquier momento que se inicie el control prenatal.

Disponibilidad de los medicamentos antirretrovirales, en las presentaciones oral (tabletas y jarabe) e intravenosa que se indican en estas guías. El personal de salud encargado de ofrecer estos medicamentos debe conocer su correcta dosificación y utilización, sus efectos adversos, sus contraindicaciones y los efectos reportados sobre el feto y el recién nacido, para ofrecer la consejería adecuada a la madre VIH+.

Educación continua del personal de salud a todos los niveles de atención para que la estrategia se desarrolle sin interrupciones.

\footnotetext{
Abreviaturas: VIH: virus de inmunodeficiencia humana; TARV: terapia antirretroviral; CVIHa: clínica VIH/Sida de adultos; CVIH-HNN: clínica de infección por VIH Hospital Nacional de Niños.

Correspondencia: María Paz León Bratti, División de inmunología, Hospital México. Correo electrónico: clínica_vih_hm@yahoo.com. Oscar Porras Madrigal, apartado 1654-1000 San José, Costa Rica. Correo electrónico: oporrasm@cariari.ucr.ac.cr.
}

\section{Actividades para la Prevención Perinatal del VIH}

- Tamizaje con ELISA-VIH de la mujer embarazada.

- Terapia antirretroviral (TARV) para la mujer embarazada VIH+.

- Recomendación de vía de parto para la mujer embarazada VIH+.

- Consejería para la madre VIH+ sobre adherencia al tratamiento, lactancia materna, sexo seguro, embarazo y esterilización.

- Atención de la madre en la Clínica VIH /Sida de adultos (CVIHa).

- Atención en el periodo neonatal del hijo (a) de madre $\mathrm{VIH}+$.

- Atención del hijo (a) de madre VIH+ en la Clínica de Infección por VIH del Hospital Nacional de Niños "Dr. Carlos Sáenz Herrera" (CVIH-HNN).

\section{Tamizaje de la mujer embarazada}

Todas las mujeres que acuden a la primera consulta prenatal, deben recibir consejería sobre los beneficios del tamizaje prenatal para VIH. Después de obtener el consentimiento de la mujer para que se realice la prueba de ELISA-VIH, obtener $5 \mathrm{cc}$ de sangre total por punción de una vena periférica, depositarlos en un tubo sin anticoagulante, separar el suero y enviarlo con una orden para "ELISA VIH".

Los casos con ELISA-VIH reactivo deben ser reportados de inmediato al personal de salud que atendió la consulta prenatal. Con la información del ELISA-VIH se debe citar a la madre, explicarle el resultado y referirla de inmediato a la CVIHa que le corresponda según el área de atracción: Monseñor Sanabria, México, San Juan de Dios, Calderón Guardia. Es conveniente notificar del caso por teléfono al personal de la CVIHa. 
A nivel de la CVIHa se solicitará un segundo ELISA-VIH y la prueba de Western-Blot. Esta segunda muestra se obtiene igual que la primera; en la orden indicar "ELISA-VIH muestra \#2, si es reactiva enviar el suero para Western-Blot". El resultado de esta segunda muestra debe ser reportado lo antes posible a la CVIHa y la paciente debe ser citada lo antes posible para consejería, discusión de los resultados y para ofrecerle el tratamiento adecuado a las madres VIH+.

La CVIHa referirá a la paciente al Servicio de Obstetricia correspondiente para el manejo, seguimiento y decisión conjunta de la vía de parto. No es necesario que el servicio de Obstetricia solicite nuevos ELISA-VIH a la paciente.

\section{Terapia antirretroviral (TARV) de la mujer embarazada VIH +}

La embarazada VIH+ de acuerdo con su estadío clínico, inmunológico y virológico será candidata a recibir durante el embarazo dos tipos diferentes de TARV. Si cumple con los criterios del protocolo nacional de manejo de adultos VIH+ (manifestaciones clínicas de VIH, CD4 <350 o carga viral > 30000 copias $/ \mathrm{ml}$ ) es candidata a recibir TARV triasociada. Si no cumple los criterios para TARV triasociada es candidata a recibir AZT durante el embarazo.

La CVIHa será la encargada de explicar a la madre los resultados de sus estudios de laboratorio, el tratamiento con antirretrovirales que se propone y sus beneficios, efectos adversos, contraindicaciones y las ventajas y desventajas para el recién nacido. Se debe aprovechar para discutir con la madre todos los elementos que componen la estrategia de prevención para la transmisión perinatal del VIH. La madre informada adecuadamente debe firmar un consentimiento escrito para iniciar o continuar con el uso de antirretrovirales durante el embarazo.

Las mujeres embarazadas $\mathrm{VIH}+$ referidas o en control en las CVIHa pueden presentar, dependiendo del momento de referencia y de su experiencia con el uso de antirretrovirales, las siguientes situaciones:

2.1: Mujeres VIH+, con 14 o más semanas de gestación, sin TARV previa sin manifestaciones clínicas atribuibles a la infección por VIH.

Estas mujeres deberán recibir:

2.1a. Zidovudina oral (AZT, Retrovir $\left.{ }^{\circledR}\right) 300 \mathrm{mg}$ cada 12 horas a partir de la semana 14 de gestación o al momento de su detección y durante todo el embarazo. La presentación de Zidovudina es en cápsulas de 100mg. Este tratamiento se descontinuará en el post-parto. Este tratamiento no busca modificar la infección materna por VIH, sólo sirve para prevenir la transmisión perinatal.

2.1b. Zidovudina intravenoso (AZT, Retrovir ${ }^{\circledR}$ ) durante el periodo de labor a $2 \mathrm{mg} / \mathrm{Kg}$ de peso corporal a pasar en una hora, luego continuar con una infusión de $1 \mathrm{mg} / \mathrm{Kg}$ de peso corporal por hora hasta el nacimiento, independientemente de la duración de la labor de parto. Suspender la Zidovudina que recibe la paciente por vía oral. En caso de cesárea programada, iniciar la Zidovudina intravenosa con las indicaciones anteriores, 3 horas antes del inicio de la cirugía y luego mantener la infusión hasta que se complete el nacimiento. La presentación de la Zidovudina intravenosa es frascos de $20 \mathrm{ml}$ con $200 \mathrm{mg}$, es decir $10 \mathrm{mg}$ por $\mathrm{ml}$. Se debe diluir en Solución de Dextrosa al 5\% o Solución Salina, la concentración no debe exceder $4 \mathrm{mg}$ por $\mathrm{ml}$. La solución preparada es estable 8 horas a temperatura ambiente o 24 horas en refrigeración.

Si no hay Zidovudina intravenosa disponible, se debe mantener la Zidovudina por vía oral $300 \mathrm{mg}$ (3 cápsulas) cada 3 horas durante el periodo de labor y hasta el nacimiento, administrando la última dosis 3 horas antes de la cesárea. Se puede utilizar el AZT que la madre ha estado tomando durante el embarazo o se deben conseguir las cápsulas de $100 \mathrm{mg}$ de Zidovudina.

2.1.c. Notificar al neonatólogo o al pediatra para que discuta con la madre las indicaciones de prevención para el recién nacido (Punto 6 de estas guías).

\section{2: Mujeres VIH+, con 14 o más semanas de gestación sin TARV previa, con indicación para triple TARV.}

2.2.a. Si la paciente cumple con los criterios clínicos para recibir triple TARV, se le debe brindar la consejería y educación necesarias para iniciar cuanto antes TARV con AZT (300mg c/12 hs, igual que en 1 a), 3TC y Nelfinavir. Si por algún motivo existe algún inconveniente para iniciar la triple TARV, la paciente debe iniciar lo antes posible al menos con AZT oral (recomendación 1 a).

2.2.b. 3TC (Lamivudina, Epivir ${ }^{\circledR}$ ) tabletas de $150 \mathrm{mg}$. Dosis: $150 \mathrm{mg}$ cada 12 horas.

2.2.c. Nelfinavir (Viracept ${ }^{\circledR}$ ) tabletas de $250 \mathrm{mg}$. Dosis: 750 $\mathrm{mg}$ cada 8 horas ó $1250 \mathrm{mg}$ cada 12 horas.

2.2.d. Implementar las indicaciones $2.1 \mathrm{~b}, 2.1 \mathrm{c}$ y el punto 6 .

\section{3: Mujeres VIH+ con TARV que se inició antes del embarazo.}

Explicar a la madre el tratamiento con antirretrovirales que se propone (durante el embarazo, parto y periodo neonatal) y sus beneficios, efectos adversos, contraindicaciones y las ventajas y desventajas para el recién nacido.

2.3.a. Continuar con la TARV que la mujer esta recibiendo. Si el esquema no incluye AZT, se debe modificar el mismo para que reciba Zidovudina como parte de su TARV, explicándole a la madre el motivo. 
2.3.b. Si está recibiendo Efavirenz, se le debe suspender lo antes posible, modificar el esquema de TARV y discutir con la madre el riesgo para el feto por la exposición a Efavirenz.

2.3.c. Implementar las indicaciones $2.1 \mathrm{~b}, 2.1 \mathrm{c}$ y el punto 6 .

2.4: Mujeres VIH+, en el periodo de labor, sin TARV previa.

2.4.a. Implementar las indicaciones $2.1 \mathrm{~b}, 2.1 \mathrm{c}$ y el punto 6 .

2.5: Mujeres VIH+, que rehusan el uso de TARV durante el embarazo.

2.5.a. Se les debe dar la consejería adecuada e insistir sobre los beneficios para el recién nacido de la TARV. Si persiste en su decisión, debe escribirse una nota en el expediente que indique la decisión de la madre y esta la deber firmar la paciente y al menos un testigo.

2.5.b. Implementar las indicaciones $2.1 \mathrm{~b}$ y $2.1 \mathrm{c}$ y el punto 6 .

\section{Vía de parto para la mujer embarazada VIH positiva}

Existe amplia evidencia médica, tanto de estudios observacionales como al azar, que demuestra que la cesárea electiva (antes del inicio de labor y de la ruptura de membranas) disminuye por sí sola el riesgo de transmisión perinatal del VIH. También se ha demostrado que mientras más instrumentado y prolongado sea el parto vaginal, mayor es el riesgo de transmisión perinatal del VIH. Por tanto las recomendaciones en cuanto a vía de parto son:

3.1: Mujeres VIH+, en TARV recibiendo sólo AZT o recibiendo TARV triple con carga viral $>1000$ copias $/ \mathrm{ml}$.

Estas pacientes tienen recomendado un parto por cesárea programada a la semana 38 de gestación. Se deben implementar las indicaciones $2.1 \mathrm{~b}$ y $2.1 \mathrm{c}$ y el punto 6 .

\section{2: Mujeres VIH+ en TARV triple con carga viral no detectable.}

Programar un parto por vía vaginal, excepto que existan contraindicaciones obstétricas. El riesgo de transmisión perinatal con esta carga viral es de $2 \%$ o menos, independientemente de la vía de parto. Se deben implementar las indicaciones $2.1 \mathrm{~b}$ y $2.1 \mathrm{c}$ y el punto 6 .

3.3: Mujeres VIH+, en las cuales está indicado un parto por cesárea programada pero éste no es posible de realizar.

3.3.a. Se debe realizar un parto por via vaginal, con el mínimo de trauma posible, no instrumentado y sin ruptura artificial de membranas

3.3.b. Implementar las indicaciones $2.1 \mathrm{~b}$ y $2.1 \mathrm{c}$ y el punto 6 .

\section{Consejería para la madre $\mathrm{VIH}+$ sobre - adherencia al tratamiento, lactancia materna, sexo seguro, embarazo y este- rilización.}

A nivel de la CVIHa y de la consulta prenatal, se debe iniciar un proceso de consejería con la mujer embarazada y su pareja sobre las posibilidades de transmisión del VIH de la madre al niño,

la importancia de la adherencia al TARV y de evitar la lactancia materna, planificación de futuros embarazos, posibilidades de esterilización y prácticas de sexo seguro. Dado que en la actualidad la madre puede recibir TARV altamente efectiva que baje su carga viral hasta niveles no detectables, no se debe considerar la infección por VIH como una indicación 'absoluta' de esterilización.

\section{Seguimiento de la madre $\mathrm{VIH}+$ en la CVIHa}

A nivel de la CI-VIHa se tomaran las disposiciones necesarias para el seguimiento y tratamiento de la madre después del parto.

\section{Atención en el periodo neonatal del hijo (a) de madre VIH+}

Profilaxis con Zidovudina: el recién nacido debe iniciar tratamiento profiláctico con Zidovudina a las 8 horas de edad, el tratamiento debe mantenerse durante 6 semanas. La Zidovudina se debe dar sin mezclarla con alimentos, a una dosis de 2 $\mathrm{mg} / \mathrm{Kg}$ de peso corporal/dosis cada 6 horas. Se debe utilizar la presentación de jarabe, que contiene $10 \mathrm{mg} / \mathrm{ml}$ en frascos de $100 \mathrm{ml}$.

Suspensión de la lactancia materna: se le debe explicar a la madre que existe evidencia de que el virus VIH se puede transmitir a través de la leche materna y que este factor de riesgo se debe evitar suspendiendo la lactancia materna. Se le debe indicar a la madre que contará con el suministro mensual de una fórmula a base de leche de vaca.

Suspensión de la vacunación con BCG: informar a la madre que esta vacuna está compuesta por una bacteria viva, atenuada y explicarle que puede darse el riesgo de diseminación si su hijo presenta defectos en la función de su sistema inmune, como consecuencia de la infección por VIH.

Referencia: reportar el caso para seguimiento y para obtener la cita de control, al servicio de Inmunología del Hospital Nacional de Niños "Dr. Carlos Sáenz Herrera, en forma personal o al teléfono 2235125 o 2220122 extensión 464. La hora más adecuada para comunicarse es de 10-11 am de Lunes a Viernes. 


\section{Atención del niño(a) en la CIVH-HNN}

Durante el período en que se define si el/la hijo/a de madre VIH+ está infectado/a o no, el niño/a debe recibr durante los primeros 18 meses de edad la atención a los aspectos de crecimiento, desarrollo psicomotor y vacunación.

En la vacunación, se evita el uso de vacunas con virus o bacterias vivas. No se utiliza BCG y se sustituye la vacuna de Polio oral, por una vacuna de Polio parenteral con base en virus muertos, esto evita también el riesgo de polio asociado a la vacunación en otros miembros de la familia con inmunodeficiencia.

La profilaxis con Trimetroprin/sulfametozaxol evita que la pneumonitis interticial por Pneumocystis carinii sea la patología de inicio en los casos de niños (as) que se han infectado por VIH.

Se debe procurar el diagnóstico temprano de infección por $\mathrm{VIH}+$, con la determinación de PCR-ADN en las células mononucleares del niño (a), lo cual permite suspender medicamentos innecesarios cuando no hay infección o iniciar el TARV en los casos en los que se demuestre la transmisión del VIH de la madre al niño (a).

En los pacientes identificados como serovertores, es decir no infectados por VIH, se continua su control anual por 5 años.

Los pacientes infectados por VIH continúan su tratamiento en la consulta correspondiente de la CVIH-HNN.

\section{Referencias:}

1. Public Health Service Task Force. Recommendations for the use of antiretroviral drugs in pregnant IHV-1 infected women for maternal health and interventions to reduce perinatal HIV-1 transmissions in the United States. http//www.hivatis.org. Jan 24/2001.

2. Connor EN, Sperkling RS, Gelber R et al. Reduction of maternal-infant transmission of human immunodeficiency virus type I with zidovudine treatment. N Engl J Med 1994, 331:1173-1180.

3. The european mode of delivery collaboration. Elective cesarean section versus vaginal delivery in prevention of vertical HIV-1 transmission: a randomized clinical trial. Lancet 1999, 353:1035-1039.

4. The international perinatal HIV group. The mode of delivery and the risk of vertical transmission of HIV-1- a meta-analysis of 15 prospective cohort studies. N Engl J Med 1999; 340:977-987. 